\title{
QUALIFICAÇÃO E INTERNACIONALIZAÇÃO EMPRESARIAL: ATENDIMENTO DAS DEMANDAS DE CLIENTES DO PROGRAMA PEIEX/UNIVALI
}

\author{
DAIANe Miranda ${ }^{1}$ \\ ORCID: 0000-0001-8398-1024 \\ LÍGIA GHISI ${ }^{2}$ \\ ORCID: 0000-0001-8929-0953 \\ WALDIR GOEDE ${ }^{3}$ \\ ORCID: 0000-0001-8049-7712
}

\begin{abstract}
Resumo: A internacionalização é um dos desafios empreendidos por uma empresa para se tornar competitiva e sustentável frente à concorrência internacional. A Agência Brasileira de Promoção de Exportações e Investimentos (APEX-BRASIL), por meio do Programa de Qualificação para Exportação (PEIEX), desenvolve ações de fomento ao comércio exterior. Executado entre 2017 e 2019, o PEIEX/UNIVALI atendeu 148 empresas no Vale do Itajaí. Este trabalho analisa o índice de atendimento as demandas sugeridas às empresas participantes. Aplicou-se o método de pesquisa qualitativa com uma abordagem quantitativa e, elaborouse uma amostra não aleatória intencional de 40 organizações. Os resultados mostram que,
\end{abstract}

1 Extensionista do programa de Qualificação para Exportação - PEIEX/UNIVALI, Graduada em Comércio Exterior, Pós-graduanda em Gestão Financeira. E-mail: (miranda.daiane82@gmail.com).

2 Professora universitária, Extensionista do programa de Qualificação para Exportação - PEIEX/UNIVALI, Graduada em Administração, Mestre em Turismo e Hotelaria. E-mail: (ligia@univali.br).

3 Professor universitário, Extensionista do programa de Qualificação para Exportação - PEIEX/UNIVALI, Graduado em Economia, Mestre em Administração. E-mail: (wgoede@univali.br). 
das 191 demandas sugeridas, 77 foram priorizadas (40\%), 42 parcialmente (22\%) e 72 não priorizadas (38\%). No âmbito do comércio exterior, as demandas representaram 152 ações (79,5\%), das quais 57 foram priorizadas, 39 parcialmente e 56 ainda não priorizadas até o final do período (abril/2019).

Palavras-chave: Internacionalização, PEIEX, Demandas.

\title{
QUALIFICATION AND BUSINESS INTERNATIONALIZATION: ANALYZING PEIEX / UNIVALI CUSTOMER SERVICE
}

\begin{abstract}
Internationalization is one of the challenges that a company undertakes to become competitive and sustainable against the international competition. The Brazilian Export and Investment Promotion Agency (APEX-BRAZIL), through the Export Qualification Program (PEIEX), develops actions to promote foreign trade. Held between 2017 and 2019, PEIEX / UNIVALI served 148 companies in Vale do Itajaí. This paper analyzes the attendance rate to the demands suggested to the participating companies. The qualitative research method of quantitative approach was applied, and an intentional non-random sample of 40 organizations was elaborated. The results show that, from the 191 suggested demands, 77 were prioritized (40\%), 42 partially prioritized (22\%) and 72 were not prioritized (38\%). In the area of foreign trade, the demands represented 152 actions (79.5\%), where 57 were prioritized, 39 partially prioritized and 56 were not yet prioritized until the end of the period (April / 2019).
\end{abstract}

Keywords: Internationalization. PEIEX. Demands.

\section{CUALIFICACIÓN E INTERNACIONALIZACIÓN EMPRESARIAL: ATENCIÓN A LAS DEMANDAS DE CLIENTES DEL PROGRAMA PEIEX / UNIVALI}

Resumen: La internacionalización es uno de los desafíos que una empresa emprende frente a la competencia internacional. La Agencia Brasileña de Promoción de Exportaciones e Inversiones (APEX-BRASIL), a través del Programa de Cualificación para Exportaciones (PEIEX), desarrolla acciones para promover el comercio exterior. Ejecutado entre 2017 y 2019, PEIEX / UNIVALI prestó servicios a 148 empresas en Vale do Itajaí. Este artículo científico analiza la tasa de asistencia a las demandas de las empresas participantes. El método de investigación cualitativa se aplicó con enfoque cuantitativo y se desarrolló una muestra no aleatoria intencional de 40 organizaciones. Los resultados muestran que de las 191 demandas sugeridas, 77 fueron priorizadas (40\%), 42 parcialmente (22\%) y 72 no priorizadas (38\%). En el área de comercio exterior, las demandas representaron 152 acciones (79.5\%), de las cuales 57 fueron priorizadas, 39 parcialmente y 56 aún no priorizadas hasta el final del período (abril/2019).

Palabras claves: Internacionalización, PEIEX, Demandas.

Submetido em: 27/08/2019.

Aceito em: 12/09/2019. 


\section{INTRODUÇÃO}

No contexto da abertura comercial, após a segunda década do século XX, em função da competição econômica internacional, muitas empresas foram levadas a fazer adaptações para manter e até aumentar sua participação nos mercados. Neste ambiente, à medida que o processo de internacionalização avança, também cresce a alocação de recursos para operações externas. Desta forma, novas teorias são formuladas para abordar a internacionalização das organizações durante o último século.

O processo de internacionalização é uma operação dinâmica e complexa, necessária para que as empresas possam sobreviver e competir no ambiente globalizado. No Brasil, a internacionalização das empresas ocorreu de forma tardia (late mover), pois elas se encontravam inseridas em uma atmosfera de incertezas e descontinuidades, mas parcialmente protegidas da competição externa devido a diferentes formas de protecionismo. Com a progressiva abertura econômica na década de 1990 e após o Plano de Estabilização de 1994, gerou-se maior equilíbrio econômico. Tal cenário induziu a necessidade de as empresas serem mais competitivas frente à concorrência internacional.

O tema internacionalização empresarial vai ao encontro das atividades da Agência Brasileira de Promoção de Exportações e Investimentos (APEX-BRASIL) que, por meio do PEIEX - Programa de Qualificação para Exportação, desenvolve ações de fomento para auxiliar empresas de médio e pequeno porte a atuarem para ampliar suas operações de comércio exterior. No apoio ao processo de internacionalização, destacam-se ações que envolvem inteligência de mercado, promoção comercial, de negócios e de imagem, qualificação empresarial, atração de investimentos, entre outras.

Com base nestes preceitos, o Núcleo Operacional PEIEX Vale do Itajaí PEIEX/UNIVALI aplicou metodologia própria de diagnóstico, demandas e acompanhamento do cumprimento destas recomendações em 148 empresas, no período de 2017 a 2019. Como o Núcleo possui uma vasta base de dados sobre o trabalho prestado a estas empresas, identificou-se a seguinte questão problema: Qual foi o índice de atendimento às demandas formuladas às empresas que participaram do programa PEIEX/UNIVALI, no período 2017/2019?

Com base no questionamento inicialmente proposto, o trabalho analisa o "nível de qualificação" para o comércio exterior, tomando como base o 
atendimento das demandas nas empresas participantes do Programa PEIEX/ UNIVALI. Observando a área de atuação das empresas que participaram desta etapa do Programa PEIEX/UIVALI, concomitantemente, o trabalho traça um perfil dessas empresas, categoriza o status de implantação das demandas sugeridas pelos técnicos extensionistas e avalia as principais recomendações da área funcional de comércio exterior.

A estratégia metodológica foi desenvolvida com base em abordagem qualitativa e quantitativa. A base das informações empíricas foi o levantamento de dados obtidos a partir do cotejamento das demandas sugeridas no Relatório Diagnóstico, com base no qual gerou-se o Formulário do Plano de Atendimento das Demandas e o atendimento das mesmas, verificados no Relatório Final das atividades de extensão, os quais foram aplicados a todas empresas atendidas pelo Programa.

Busca-se, com os resultados, obter um registro sintético da atuação da equipe do Núcleo PEIEX/UNIVALI, identificar o desempenho empresarial e analisar a eficácia das ações do Programa. Acredita-se que a compilação dos dados contribuirá nas ações futuras de planejamento do Núcleo, pois isto ampliará a expertise e o sucesso das empresas que desejam operar no mercado internacional.

\section{A INTERNACIONALIZAÇÃO DE EMPRESAS}

A internacionalização de empresas é um processo em que a empresa adapta suas operações aos ambientes internacionais (CALOF; BEAMISH, 1995) e, na visão de Root (1994), engloba diferentes modos de atuação no exterior, como exportação, licenciamento, joint-ventures, aquisições e investimento direto estrangeiro.

A evolução dos conceitos de internacionalização, com base em alguns autores nacionais e internacionais, é sintetizada no quadro 01, a seguir.

\begin{tabular}{|l|l}
\hline \multicolumn{1}{|c|}{ AUTORES/ANO } & \multicolumn{1}{c}{ A INTERNACIONALIZAÇÃo } \\
\hline Johanson e Wiedesheim-Paul (1975) & $\begin{array}{l}\text { É a consequência de uma série de decisões } \\
\text { incrementais e somatórias. Processo pelo } \\
\text { qual as empresas gradualmente aumentam } \\
\text { seu envolvimento em negócios internacionais, } \\
\text { o que implica posições em redes (networks) } \\
\text { no exterior. As decisões do processo de } \\
\text { internacionalização serão determinadas, } \\
\text { direta ou indiretamente, pelas relações } \\
\text { no interior das redes de negócios. }\end{array}$ \\
\hline
\end{tabular}




\begin{tabular}{|l|l|}
\hline Welch e Luostarinen (1988) & $\begin{array}{l}\text { Processo de envolvimento crescente em } \\
\text { operações internacionais, no sentido } \\
\text { do contexto doméstico para mercados } \\
\text { estrangeiros e vice-versa. }\end{array}$ \\
\hline $\begin{array}{l}\text { Cavusgil e Kirpalani (1993), } \\
\text { Sullivan (1994) e Reuber e Fischer (1997). }\end{array}$ & $\begin{array}{l}\text { Referem-se à internacionalização como } \\
\text { "grau de internacionalização" (Degree Of } \\
\text { Internationalization - DOI). }\end{array}$ \\
\hline Knight e Liesch (2002) & $\begin{array}{l}\text { Ocorre quando a empresa expande sua venda, } \\
\text { produção ou outras atividades de negócios } \\
\text { nos mercados internacionais. }\end{array}$ \\
\hline Jones e Coviello (2005) & $\begin{array}{l}\text { É um processo e, por definição, } \\
\text { o comportamento de internacionalização } \\
\text { ocorre ao longo do tempo, manifestando-se } \\
\text { na sequência em que os eventos ocorrem. }\end{array}$ \\
\hline Fleury e Fleury (2011) & $\begin{array}{l}\text { É o fenômeno relacionado aos agentes } \\
\text { e atores sociais que participam do processo } \\
\text { de globalização. }\end{array}$ \\
\hline Oesterle, Richta e Fisch (2013) & $\begin{array}{l}\text { É a diversificação e extensão do negócio } \\
\text { além das fronteiras. }\end{array}$ \\
\hline
\end{tabular}

\section{QUADRO 1: EVOLUÇÃO DO CONCEITO DE INTERNACIONALIZAÇÃO DE EMPRESAS.}

FONTE: AdAPTADO dE SOUZA E FENILI (2012).

As teorias de internacionalização são divergentes em suas abordagens e perspectivas de análise, sendo classificadas em dois eixos de pesquisa, um de viés econômico e outro de viés comportamental.

\section{Teorias de Internacionalização}

As principais abordagens de viés econômico são as teorias do Poder de Mercado de Hymer, do Ciclo de Vida do Produto de Vernon, dos Custos de Transação de Williamson, da Internalização de Buckley e Casson e do Paradigma Eclético $(\mathrm{OLI}=$ owneship, location, internalization $)$ de Dunning. De acordo com as abordagens econômicas, se uma empresa decide expandir-se por meio da exportação, ela enfrentará custos, sejam eles associados à busca de informação ou ao cumprimento de contratos, adaptação empresarial, poder do produto ou até à absorção de processos produtivos para gerar vantagem competitiva.

$\mathrm{Na}$ abordagem das teorias comportamentais, há a relação com o comportamento na tomada de decisões, as redes utilizadas e, ainda, do próprio gestor no processo internacional. As teorias mais citadas são o Modelo da Escola de Uppsala, a Teoria das Redes (networks) e o Empreendedorismo Internacional. O Quadro 02 apresenta as principais abordagens das Teorias Comportamentais e suas características. 


\begin{tabular}{|c|c|c|}
\hline AUTOR (ANO) & TEORIA & CARACTERÍSTICAS \\
\hline $\begin{array}{l}\text { Johanson e Wiedersheim-Paul } \\
\text { (1975) e Johanson e Vahlne } \\
(1977,1990)\end{array}$ & Escola de Uppsala & $\begin{array}{l}\text { O modelo tem caráter dinâmico, } \\
\text { pois o aprendizado gradual permite } \\
\text { a entrada em novos mercados, em } \\
\text { um processo sequencial e contínuo } \\
\text { de internacionalização. Os pontos } \\
\text { focais são a distância psíquica e o } \\
\text { comprometimento gradual com } \\
\text { mercados, por meio de estágios } \\
\text { sequenciais. }\end{array}$ \\
\hline $\begin{array}{l}\text { Johanson e Vahlne } \\
(1990,2003,2009)\end{array}$ & Networks & $\begin{array}{l}\text { A inserção em networks permite às } \\
\text { empresas acessar rapidamente novos } \\
\text { mercados e aprender sobre suas } \\
\text { condições de negócios e processos } \\
\text { de internacionalização, para se } \\
\text { adaptarem mais facilmente a contextos } \\
\text { institucionais diversos aos de seus } \\
\text { países de origem. }\end{array}$ \\
\hline $\begin{array}{l}\text { McDougall (1989); Oviatt e } \\
\text { McDougall (1994) e Johanson } \\
\text { e Vahlne (2003) }\end{array}$ & $\begin{array}{l}\text { Empreendedorismo } \\
\text { Internacional }\end{array}$ & $\begin{array}{l}\text { A visão do empreendedorismo } \\
\text { internacional visa explicar a expansão } \\
\text { internacional de novas empresas ou } \\
\text { start-ups, por meio da análise de como } \\
\text { os empreendedores reconhecem e } \\
\text { exploram oportunidades. }\end{array}$ \\
\hline
\end{tabular}

QUADRO 2: PRINCIPAIS ABORDAGENS DAS TEORIAS COMPORTAMENTAIS E SUAS CARACTERÍSTICAS. FonTE: AdAPTADO de Goede (2017)

Para o Modelo de Uppsala, a evolução internacional ocorre de maneira gradual, tendo como base a Teoria de Redes (Networks) enquanto fator chave de união do processo de internacionalização (JOHANSON; VAHLNE, 2011). Na abordagem da teoria do Empreendedorismo Internacional (OVIATT; MCDOUGALL, 1994), os novos empreendimentos (start-ups) com sustentabilidade internacional geram valor em diversos países a partir de determinados ativos, primordialmente, o conhecimento.

\section{APEX-BRASIL E PEIEX}

A APEX-BRASIL é uma Agência do governo brasileiro, vinculada ao Ministério das Relações Exteriores, consistindo em um serviço social autônomo com a missão de contribuir para a internacionalização das empresas brasileiras, promover as exportações de produtos e serviços, e atrair investimentos estrangeiros diretos para o país (APEX-BRASIL, 2019).

Conforme informações disponibilizadas pela APEX-BRASIL (2019) esta agência possui escritórios de negócios no país e no exterior, onde atua em parceria com embaixadas e consulados brasileiros. Para auxiliar o processo de entrada 
no comércio internacional, a Agência oferece um portfólio de programas que envolvem qualificação empresarial, ampliação da competitividade, inteligência estratégica, ações de promoção comercial (feiras, missões empresariais, rodadas de negócios) e internacionalização.

Uma de suas principais estratégias de apoio às empresas que buscam se internacionalizar é o PEIEX - Programa de Qualificação para Exportação. O PEIEX prepara as empresas para iniciar o acesso a mercados internacionais de forma planejada e segura. Este programa é implementado no país por meio de convênios com instituições de ensino (universidades, parques tecnológicos, fundações de amparo à pesquisa) ou federações da indústria (APEX-BRASIL, 2013).

Com intuito de fortalecer as cadeias produtivas nacionais e ampliar sua competitividade interna e externa, o PEIEX promove atividades em localidades onde há concentração empresarial, ao oferecer às empresas soluções gerenciais, ações relativas à busca de informação qualificada, adequação de produtos e acesso aos mercados. O Programa também atua na melhoria da competitividade empresarial, bem como na identificação dos potenciais das empresas para inserção internacional. Neste processo é privilegiado, inicialmente, o atendimento de empresas que ofertam produtos com potencial de exportação (APEX-BRASIL, 2013).

Os parceiros conveniados à APEX-BRASIL aplicam a metodologia do PEIEX na qualificação de empresas. $\mathrm{O}$ atendimento é gratuito e feito por profissionais especialistas e professores extensionistas, com base em visitas às empresas e orientação dadas aos empresários sobre os caminhos para o mercado externo (APEX-BRASIL, 2019).

\section{Parceria entre a APEX-BRASIL e a UNIVALI}

Na Região do Vale do Itajaí, a APEX-BRASIL atua através de Convênio com a Universidade do Vale do Itajaí (UNIVALI), oficializado em 2017 mediante assinatura do Convênio de Cooperação Técnica e Financeira no 48-06/2016 (vigente por dois anos - maio/2017 - maio/2019) (FUNDAÇÃO UNIVERSIDADE DO VALE DO ITAJAÍ, 2016). A parceria com a UNIVALI decorre do fato de a instituição ofertar formação especializada em Comércio Exterior e Relações Internacionais, tanto na graduação como na pós-graduação. O portfólio da UNIVALI também contempla atividades de extensão nestes dois campos, compatíveis com as ações da APEX-BRASIL: o laboratório de ensino de assessoria e consultoria em Comércio Exterior (denominado de Trade Júnior) e o Escritório de Relações Internacionais (ERI), ambas iniciativas voltadas à área corporativa, na oferta de assessoria para empresas nos campos da diplomacia corporativa, estudo de 
inteligência comercial, pesquisas de mercado internacional, além de outros serviços que proporcionam a prática em negócios internacionais focados no cliente.

Com a parceria entre a APEX-BRASIL e a UNIVALI o Núcleo Operacional do PEIEX de Itajaí atendeu, ao longo de dois anos, 148 empresas na região do Vale do Itajaí, capacitando-as para iniciarem a comercialização de seus produtos no mercado internacional. Durante o atendimento, a empresa é acompanhada por um técnico que, após o diagnóstico, ajuda a organização a cumprir as etapas necessárias para tornar-se apta a desenvolver um plano de exportação (APEX-BRASIL, 2017). Os principais setores atendidos pelo Núcleo foram: Têxtil, Metalomecânico, Cosmético e Farmacêutico, Químico, Plástico, Tecnologia e Sistemas, Alimentos e Bebidas, Móveis e Decorações, Esporte e Cultura e Construção. As empresas atendidas estão sediadas nos municípios de Itajaí, Balneário Camboriú, Blumenau, Brusque, Gaspar, Ilhota, Indaial, São João Batista, Tijucas, Timbó e Pomerode.

\section{A Metodologia PEIEX de apoio à exportação}

O PEIEX desenvolve uma metodologia inicial com as empresas que aceitam participar do programa. Estas são avaliadas e, após a composição de diagnóstico, informadas sobre as melhorias internas necessárias ao aumento de sua competitividade e eficiência, para participação nas ações de fomento às exportações.

Com base na avaliação da estrutura produtiva, um planejamento inicial é sintetizado no Plano de Atendimento de Demandas. Após o levantamento das informações (check-list), são elaborados um diagnóstico e um plano de trabalho (demandas) com os requisitos necessários à exportação. As sugestões técnicas são propostas às empresas e, mediante negociação, define-se o período para início da sua efetivação. Ao findar o prazo, a empresa é novamente avaliada e entrega-se um documento registrando a conclusão desta fase, o qual informa o quanto a empresa priorizou e se está qualificada para atuar no comércio exterior.

Ao final do atendimento, a empresa estará apta a desenvolver um plano de exportação e capacitada a participar de ações de promoção comercial (rodadas, missões, feiras, etc.) organizadas pela APEX-BRASIL em diferentes mercados externos.

\section{Áreas Funcionais para Avaliação e Plano de Demandas}

As empresas, segundo Maximiano (2012) são organizações sistêmicas que possuem atitudes administrativas pautadas na organização, planejamento, controle e liderança, presentes em todas as áreas funcionais. Para Chiavenato (2014) as áreas funcionais advêm da abordagem anatômica e estrutural de Fayol (1990), quando 
cita as seis funções básicas de um "corpo empresarial": técnicas, financeiras, comerciais, segurança, contábeis e administrativas. As áreas funcionais propostas por Maximiano (2012) também são seis e se referem às divisões setoriais: Administrativo, Recursos Humanos, Financeiro, Produção, Logística e Comercial.

A APEX-BRASIL (2013) adaptou o conceito das divisões setoriais para avaliar as empresas e apresentar o plano de melhorias (demandas), ao apontar a situação da empresa a partir de seus pontos fortes e de melhoria em relação às áreas funcionais: Administração Estratégica, Capital Humano, Finanças e Custos, Vendas e Marketing, Comércio Exterior, e Produto e Manufatura.

A Administração Estratégica está ligada à gestão administrativa, com ênfase em preparar as ações para o futuro, por meio da definição de objetivos e metas. Para a APEX-BRASIL (2013) fazem parte as seguintes esferas: estratégia organizacional, estrutura organizacional, indicadores de desempenho.

O Capital Humano define a política de recursos humanos para vencer os desafios, por meio da coesão e participação de todos os elementos da organização, dada a administração, estratégia, educação e treinamento de recursos humanos (APEX-BRASIL, 2013).

A área de Finanças e Custos abarca as responsabilidades do setor financeiro, desempenhando uma variedade de tarefas, tais como orçamento, previsões financeiras, administração de caixa, de crédito, análise de investimentos, administração e indicadores de custos (APEX-BRASIL, 2013).

Vendas e Marketing é um campo funcional, que busca sentir o mercado para atrair, manter seus clientes/consumidores, e estabelecer uma relação com o desenvolvimento de produtos. Tem sob sua responsabilidade a gestão política mercadológica e a análise de desempenho (APEX-BRASIL, 2013).

O Comércio Exterior, para a APEX-BRASIL (2013), é uma especificidade do PEIEX, por trabalhar com processos e fatores da engenharia de exportação, desenvolvimento e aplicação do plano de exportação, além da interação com os programas do governo de auxílio à exportação.

Produto e Manufatura é outra ramificação do processo produtivo - planejamento e desenvolvimento do produto -, no intuito de atingir os objetivos da organização. Ela envolve-se no planejamento e controle da produção, movimentação de materiais, controle de estoques e da qualidade, análise de métodos, layout e eficiência energética (APEX-BRASIL, 2013).

As áreas funcionais são requisitos que orientam na avaliação do contexto atual das empresas e na recomendação das melhorias. Cabe ao PEIEX identificar as demandas priorizadas na classificação do quanto uma empresa é qualificada 
para atuar no comércio exterior. Porém, a participação da empresa no Programa não tem data para acabar, enquanto garantia de continuidade da interação com o PEIEX nas diversas formas de promoção comercial, para fomentar cada vez mais as operações internacionais e cumprir metas relacionadas aos objetivos e compromissos da Agência (APEX-BRASIL, 2019).

\section{METODOLOGIA DA PESQUISA}

Diante da questão problema "Qual o índice de atendimento as demandas das empresas que participaram do programa PEIEX/UNIVALI no período de 2017/2019?", a pesquisa quantitativa baseou-se no levantamento de dados produzidos e registrados nos relatórios técnicos, produzidos nas diferentes etapas de atendimento às empresas. Segundo Richardson (2010), tal tipologia de investigação caracteriza-se por aplicar a quantificação em coletas e tratamento de informações, por meio de técnicas estatísticas, das mais simples às mais complexas.

Os dados examinados foram extraídos de um universo total de 148 empresas, cuja amostra é não aleatória ou intencional. Esta denominação é citada por Roesch (2010) quando explica a intenção dada pelo julgamento do pesquisador. Neste caso, foram escolhidas 40 empresas do setor têxtil, a partir de 40 relatórios de diagnóstico e do formulário/plano de demandas, tendo a pesquisa documental como procedimento básico. Tal levantamento, compilada de registros e documentos, aponta as relações entre atores e recursos na identificação dos fenômenos, como eles ocorrem e suas características (CERVO; BERVIAN, 2012).

A análise teve como base a leitura, comparação e interpretação de comprovativos, para possibilitar o posterior agrupamento e compilação dos dados, apresentados na próxima seção deste trabalho.

\section{RESULTADOS}

A partir dos dados presentes nos formulários das empresas e relatórios de conclusão, foi possível interpretar e apresentar quantitativamente suas resultantes, por meio de quadros, gráficos e tabelas, organizados conforme os objetivos deste trabalho. Inicialmente, apresenta-se o Gráfico 01, que mostra o perfil e a área de atuação das empresas participantes do PEIEX/UNIVALI.

As seis principais áreas de atuação das empresas atendidas pelo PEIEX/UNIVALI foram: Têxtil, Metalomecânica, Móveis e Decorações, Alimentos e Bebidas, Calçados, Acessórios e Cosméticos. Foram analisadas 40 empresas nas seis áreas 
descritas acima e suas respectivas demandas segundo a metodologia da APEX-BRASIL (2013). Quanto ao status da implantação das demandas, considerou-se três categorias: 1) priorizadas, 2) priorizadas parcialmente e 3) não priorizadas, apresentadas nos Quadros 03, 04 e 05.

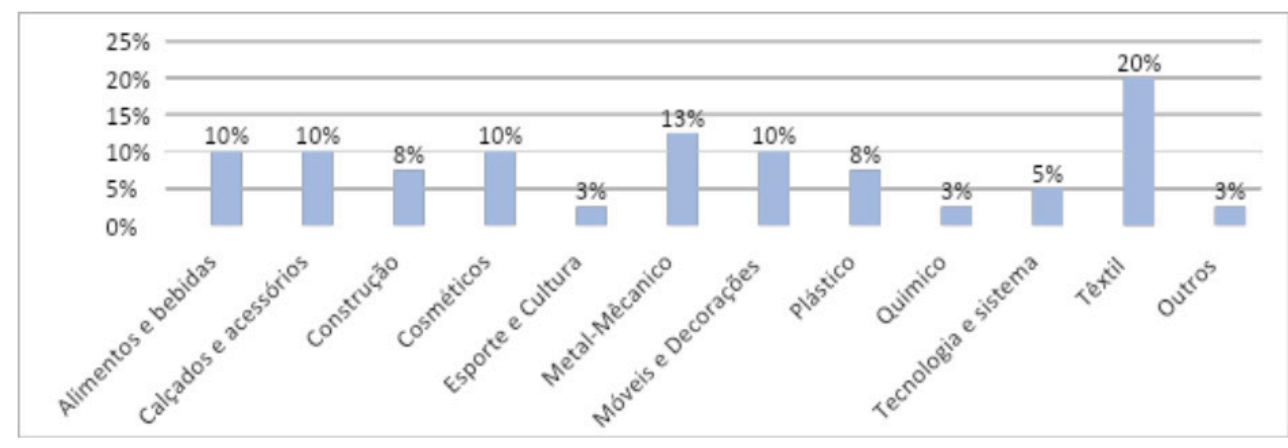

Gráfico 1: ÁreAs de ATUAÇÃo E EMPRESAS PEIEX/UNIVALI. Fonte: Elaborado PELOS PESQUISADORES (2019).

As seis principais áreas de atuação das empresas atendidas pelo PEIEX/UNIVALI foram: Têxtil, Metalomecânica, Móveis e Decorações, Alimentos e Bebidas, Calçados, Acessórios e Cosméticos. Foram analisadas 40 empresas nas seis áreas descritas acima e suas respectivas demandas segundo a metodologia da APEX-BRASIL (2013). Quanto ao status da implantação das demandas, considerou-se três categorias: 1) priorizadas, 2) priorizadas parcialmente e 3) não priorizadas, apresentadas nos Quadros 03, 04 e 05.

As 40 empresas analisadas totalizaram 191 demandas nas seis áreas funcionais, a saber: Administração estratégica (8 demandas), Capital humano (5 demandas), Comércio exterior (152 demandas), Finanças e custos (4 demandas), Vendas e marketing (11 demandas) e, Produto e manufatura (11 demandas).

Cabe ressaltar que a definição das demandas do PEIEX a serem implementadas, são consensadas pelo empresário em conjunto com o(a) técnico(a) extensionista, com base nas sugestões apresentadas no Relatório de Diagnóstico. Trata-se de uma metodologia internacional da APEX-BRASIL, amparada na matriz de identificação estratégica, cujos dados são gerados no Customer Relationship Management, forma de gestão do relacionamento com o cliente focada em colocá-lo no centro dos processos da empresa, de modo a viabilizar a antecipação das necessidades atuais e potenciais.

$\mathrm{Na}$ matriz estratégica são apontadas as seis áreas funcionais pelo seu grau de importância (pouco importante, importante, muito importante = Eficácia operacional) e o seu desempenho (ruim, bom, muito bom = Eficiência operacional). 
Após esta análise, as demandas são sugeridas e acordadas com o empresário. Não foram analisadas no status da implantação a descrição de todas as demandas priorizadas, priorizadas parcialmente e não priorizadas, porém, abarca-se sua totalidade e as áreas mais relevantes, apresentadas nos Quadros a seguir.

Quanto à Administração Estratégica, o Quadro 03 mostra três demandas: estratégia organizacional, estrutura organizacional e indicadores de desempenho. O status da implantação totalizou 8 demandas sugeridas, dentre as quais 6 de estratégia organizacional.

Esta área é vital para uma empresa de qualquer porte que possui planejamento estratégico, missão, objetivo/metas, inovações tecnológicas e ações de sustentabilidade. A maioria de suas demandas aponta o comprometimento das empresas com o planejamento estratégico na gestão empresarial.

\begin{tabular}{|c|c|c|}
\hline DESCRIÇÃO DA DEMANDA & \multicolumn{2}{|c|}{ STATUS DA IMPLANTAÇÃO } \\
\hline Estratégia Organizacional & $\begin{array}{l}\text { Priorizada } \\
\text { Priorizada parcialmente } \\
\text { Não priorizada }\end{array}$ & $\begin{array}{l}1 \\
1 \\
4\end{array}$ \\
\hline Estrutura Organizacional & $\begin{array}{l}\text { Priorizada } \\
\text { Priorizada parcialmente } \\
\text { Não priorizada }\end{array}$ & $\begin{array}{l}0 \\
1 \\
0\end{array}$ \\
\hline Indicadores de desempenho & $\begin{array}{l}\text { Priorizada } \\
\text { Priorizada parcialmente } \\
\text { Não priorizada }\end{array}$ & $\begin{array}{l}1 \\
0 \\
0\end{array}$ \\
\hline
\end{tabular}

QUADRO 3: AdMINISTRAÇÃO ESTRATÉCICA. FONTE: ELABORADO PELOS PESQUISADORES (2019).

$\mathrm{Na}$ área funcional do Capital Humano (Recursos Humanos - RH), o Quadro 04 expressa quatro demandas: estratégia de $\mathrm{RH}$, administração de $\mathrm{RH}$, educação e treinamento e indicadores de RH. No status da implantação, cinco demandas foram sugeridas e o destaque com três demandas ficou na área dos indicadores de RH, onde são elencadas questões como: se a empresa efetua avaliação de desempenho dos funcionários, se realiza pesquisa de clima/satisfação, se ocorre rotatividade, se destina um percentual do seu faturamento para investimentos em educação e treinamento, entre outras questões.

Os indicadores são ferramentas de medida que determinam o valor e a eficácia das iniciativas desenvolvidas no setor de $\mathrm{RH}$.

No Quadro 05 são apontadas quatro áreas funcionais do Comércio Exterior: engenharia de exportação, plano de exportação, programa do governo de auxílio à exportação e processo de exportação. Percebe-se a relevância desta demanda, 
base do PEIEX no sentido de oportunizar o ingresso da empresa no mercado internacional via exportações, de forma segura e planejada. No total das 152 demandas, foram sugeridas estas quatro áreas, com destaque ao plano de exportação da empresa (93 demandas), o que corrobora sua importância.

\begin{tabular}{|c|c|c|}
\hline \multirow{2}{*}{$\begin{array}{l}\text { DESCRIÇÃO DA DEMANDA } \\
\text { Estratégia de Recursos } \\
\text { Humanos }\end{array}$} & \multicolumn{2}{|c|}{ STATUS DA IMPLANTAÇÃO } \\
\hline & $\begin{array}{l}\text { Priorizada } \\
\text { Priorizada parcialmente } \\
\text { Não priorizada }\end{array}$ & $\begin{array}{l}0 \\
0 \\
0\end{array}$ \\
\hline $\begin{array}{l}\text { Administração de Recursos } \\
\text { Humanos }\end{array}$ & $\begin{array}{l}\text { Priorizada } \\
\text { Priorizada parcialmente } \\
\text { Não priorizada }\end{array}$ & $\begin{array}{l}0 \\
0 \\
0\end{array}$ \\
\hline Educação e Treinamento & $\begin{array}{l}\text { Priorizada } \\
\text { Priorizada parcialmente } \\
\text { Não priorizada }\end{array}$ & $\begin{array}{l}1 \\
0 \\
1\end{array}$ \\
\hline $\begin{array}{l}\text { Indicadores de Recursos } \\
\text { Humanos }\end{array}$ & $\begin{array}{l}\text { Priorizada } \\
\text { Priorizada parcialmente } \\
\text { Não priorizada }\end{array}$ & $\begin{array}{l}2 \\
0 \\
1\end{array}$ \\
\hline
\end{tabular}

Quadro 4: Capital Humano. Fonte: Elaborado Pelos Pesquisadores (2019).

Nesta etapa do planejamento, os gestores identificam oportunidades, necessidades, desafios e exigências vinculadas à exportação, bem como os pontos fortes e fracos de seus produtos e/ou serviços. Para montar um plano de exportação, há necessidade de avaliar a capacidade exportadora, definir o preço em moeda estrangeira e atender alguns requisitos (domínio do idioma inglês, certificações, conhecimento sobre logística internacional, normas e regulamentações do país para o qual deseja exportar, documentação e SISCOMEX, etc.).

No terceiro objetivo são detalhadas as demandas do Comércio Exterior, foco do projeto PEIEX, onde se retornará a abordar os dados relevantes do Quadro 05.

\begin{tabular}{|c|c|c|}
\hline DESCRIÇÃO DA DEMANDA & STATUS & \\
\hline Engenharia de Exportação & $\begin{array}{l}\text { Priorizada } \\
\text { Priorizada parcialmente } \\
\text { Não priorizada }\end{array}$ & $\begin{array}{l}7 \\
4 \\
2\end{array}$ \\
\hline Plano de Exportação & $\begin{array}{l}\text { Priorizada } \\
\text { Priorizada parcialmente } \\
\text { Não priorizada }\end{array}$ & $\begin{array}{l}31 \\
25 \\
37\end{array}$ \\
\hline $\begin{array}{l}\text { Programa do Governo } \\
\text { de Auxilio a Exportação }\end{array}$ & $\begin{array}{l}\text { Priorizada } \\
\text { Priorizada parcialmente } \\
\text { Não priorizada }\end{array}$ & $\begin{array}{c}14 \\
3 \\
11\end{array}$ \\
\hline Processo de Exportação & $\begin{array}{l}\text { Priorizada } \\
\text { Priorizada parcialmente } \\
\text { Não priorizada }\end{array}$ & $\begin{array}{l}5 \\
7 \\
6\end{array}$ \\
\hline
\end{tabular}

QuAdRo 5: COMÉRCIO EXTERIOR. FONTE: ElABORADO PELOS PESQUISADORES (2019). 
Em Finanças e Custos, o Quadro 06 apresenta quatro demandas: administração financeira, indicadores financeiros, administração de custos e indicadores de custos. No total, quatro demandas foram sugeridas, sendo três de administração financeira, cujo objetivo é melhorar os resultados e aumentar o valor do patrimônio por meio da geração de lucro líquido.

Nesta seara financeira, são analisadas questões como, por exemplo, se a empresa executa controle de contas a pagar/receber, possui empréstimos, se há sustentação econômica principal, se faz orçamento de investimento e despesas e se detém situação creditícia regular.

\begin{tabular}{|l|l|l}
\hline DESCRIÇÃO DA DEMANDA & \multicolumn{1}{|c}{ STATUS DA IMPLANTAÇÃO } \\
\hline \multirow{3}{*}{ Administração Financeira } & $\begin{array}{l}\text { Priorizada } \\
\text { Priorizada parcialmente } \\
\text { Não priorizada }\end{array}$ & 0 \\
& Priorizada & 0 \\
\hline \multirow{3}{*}{ Indicadores Financeiros } & Priorizada parcialmente & 0 \\
& Não priorizada & 3 \\
Administração de Custos & Priorizada & 0 \\
& Priorizada parcialmente & 0 \\
& Não priorizada & 0 \\
\hline \multirow{3}{*}{ Indicadores de Custos } & Priorizada & 0 \\
& Priorizada parcialmente & 0 \\
\hline & Não priorizada & 0 \\
\hline
\end{tabular}

QuAdRo 6: FinANÇAS E Custos. Fonte: ElABORAdo PELOS PESQUISAdORES (2019).

O Quadro 07 indica cinco áreas funcionais de Produto e Manufatura: desenvolvimento de produto, gestão da inovação, processo de manufatura, qualidade e indicadores e gestão ambiental. No total, 11 demandas foram sugeridas (10 de gestão da inovação), o que corrobora com a missão do PEIEX, ou seja, uma empresa que almeja a internacionalização precisa ter em mente que o diferencial competitivo do seu produto a distingue da concorrência, agrega valor e a torna atraente aos clientes no mercado externo.

A necessidade de desenvolver a cultura de inovação nas pessoas requer a disponibilidade de cursos, palestras, treinamentos e a alta direção da organização precisa estar comprometida com este objetivo.

$\mathrm{Na}$ área funcional de Vendas e Marketing, o Quadro 08 apresenta três demandas: avaliação de mercado, política mercadológica e análise de desempenho. No total do status da implantação, 11 demandas foram sugeridas, 7 delas para a política mercadológica. 


\begin{tabular}{|c|c|c|}
\hline \multirow{2}{*}{$\begin{array}{l}\text { DESCRIÇÃO DA DEMANDA } \\
\text { Desenvolvimento de Produto }\end{array}$} & \multicolumn{2}{|c|}{ STATUS DA IMPLANTAÇÃO } \\
\hline & $\begin{array}{l}\text { Priorizada } \\
\text { Priorizada parcialmente } \\
\text { Não priorizada }\end{array}$ & $\begin{array}{l}1 \\
0 \\
0\end{array}$ \\
\hline Gestão da Inovação & $\begin{array}{l}\text { Priorizada } \\
\text { Priorizada parcialmente } \\
\text { Não priorizada }\end{array}$ & $\begin{array}{l}6 \\
0 \\
4\end{array}$ \\
\hline Processo de Manufatura & $\begin{array}{l}\text { Priorizada } \\
\text { Priorizada parcialmente } \\
\text { Não priorizada }\end{array}$ & $\begin{array}{l}0 \\
0 \\
0\end{array}$ \\
\hline Qualidade e Indicadores & $\begin{array}{l}\text { Priorizada } \\
\text { Priorizada parcialmente } \\
\text { Não priorizada }\end{array}$ & $\begin{array}{l}0 \\
0 \\
0\end{array}$ \\
\hline Cestão Ambiental & $\begin{array}{l}\text { Priorizada } \\
\text { Priorizada parcialmente } \\
\text { Não priorizada }\end{array}$ & $\begin{array}{l}0 \\
0 \\
0\end{array}$ \\
\hline
\end{tabular}

Quadro 7: Produto e MANufatura. Fonte: Elaborado PELOS PESQUisadores (2019).

Neste sentido, a maioria das empresas analisadas está focada nesta demanda e, para se habilitarem às ações de promoção comercial da APEX-BRASIL, necessitam de algumas condições, tais como possuir catálogo/website e material promocional em língua estrangeira.

$\mathrm{Na}$ metodologia da APEX-BRASIL, a política mercadológica abrange questões importantes para as empresas, como a política de preços e prazos baseada na pesquisa mercadológica (qualitativa e quantitativa), novos lançamentos, propaganda, se possui um departamento de relacionamento com clientes, se adota política de estoque e garantia e se executa a negociação.

\begin{tabular}{|c|c|c|}
\hline DESCRIÇÃO DA DEMANDA & \multicolumn{2}{|c|}{ STATUS DA IMPLANTAÇÃO } \\
\hline Avaliação de Mercado & $\begin{array}{l}\text { Priorizada } \\
\text { Priorizada parcialmente } \\
\text { Não priorizada }\end{array}$ & $\begin{array}{l}1 \\
1 \\
0\end{array}$ \\
\hline Política Mercadológica & $\begin{array}{l}\text { Priorizada } \\
\text { Priorizada parcialmente } \\
\text { Não priorizada }\end{array}$ & $\begin{array}{l}3 \\
0 \\
4\end{array}$ \\
\hline Análise de Desempenho & $\begin{array}{l}\text { Priorizada } \\
\text { Priorizada parcialmente } \\
\text { Não priorizada }\end{array}$ & $\begin{array}{l}1 \\
0 \\
1\end{array}$ \\
\hline
\end{tabular}

QuAdRo 8: VendAs E MARKETING. Fonte: Elaborado PELOS PESQUISAdORES (2019).

A Tabela 01 sumariza as demandas nas 40 empresas analisadas por área de atuação segundo a metodologia da APEX-BRASIL. Dos totais, 191 demandas foram formalizadas nas seis áreas, sendo 77 demandas priorizadas (40\%), 42 priorizadas 
parcialmente (22\%) e 72 não priorizadas (38\%). Cabe ressaltar que a maioria das empresas priorizou demandas sugeridas (77). Quanto às demandas parcialmente priorizadas (42), a pesquisa considerou as demandas não atendidas até a entrega do relatório de conclusão dos trabalhos e/ou até o final de abril/2019.

\begin{tabular}{|c|c|c|c|c|}
\hline $\begin{array}{l}\text { ÁREAS DE } \\
\text { ATUAÇÃOO }\end{array}$ & $\begin{array}{l}\text { DEMANDAS } \\
\text { PRIORIZADAS }\end{array}$ & $\begin{array}{c}\text { DEMANDAS } \\
\text { PARCIALMENTE } \\
\text { PRIORIZADAS }\end{array}$ & $\begin{array}{l}\text { DEMANDAS } \\
\text { NÃO } \\
\text { PRIORIZADAS }\end{array}$ & $\begin{array}{c}\text { TOTAL } \\
\text { DEMANDAS }\end{array}$ \\
\hline $\begin{array}{l}\text { Administração } \\
\text { Estratégica }\end{array}$ & 2 & 2 & 4 & 8 \\
\hline Capital Humano & 3 & 0 & 2 & 5 \\
\hline Comércio Exterior & 57 & 39 & 56 & 152 \\
\hline Finanças e Custos & 3 & 0 & 1 & 4 \\
\hline $\begin{array}{l}\text { Produto e } \\
\text { Manufatura }\end{array}$ & 7 & 0 & 4 & 11 \\
\hline Vendas e Marketing & 5 & 1 & 5 & 11 \\
\hline Total Demandas & 77 & 42 & 72 & 191 \\
\hline
\end{tabular}

TABela 1: Total DE DEMANDAS NAS SEIS ÁREAS DE ATUAÇÃo COM ÊNFASE PARA O CoMÉRCIO EXTERIOR).

A Tabela 01 sumariza as demandas nas 40 empresas analisadas por área de atuação segundo a metodologia da APEX-BRASIL. Dos totais, 191 demandas foram formalizadas nas seis áreas, sendo 77 demandas priorizadas (40\%), 42 priorizadas parcialmente (22\%) e 72 não priorizadas (38\%). Cabe ressaltar que a maioria das empresas priorizou demandas sugeridas (77). Quanto às demandas parcialmente priorizadas (42), a pesquisa considerou as demandas não atendidas até a entrega do relatório de conclusão dos trabalhos e/ou até o final de abril/2019.

Muitas empresas implementam estas demandas num segundo momento em função de custos, como é o caso da elaboração do catálogo em língua estrangeira (inglês/espanhol) e o website (inglês/espanhol). Porém, outras demandas (72) não foram priorizadas pelas empresas por diversas razões. A área de alimentos e bebidas (10\%) depende do registro de licenças (para exportação) realizado pelo MAPA e, de acordo com os relatos dos clientes, a morosidade e o excesso de burocracia são empecilhos para a empresa obter esta certificação.

O objetivo principal do PEIEX é viabilizar às empresas participantes do Programa a qualificação para exportação. O processo de internacionalização é um dos desafios mais importantes que uma empresa pode empreender, porém, ela necessita conhecer as regras impostas pelo mercado externo. 
A APEX-BRASIL solicita das empresas requisitos iniciais de participação em ações de comércio exterior como, por exemplo, ter preço em moeda estrangeira, catálogo e website em língua estrangeira, capacidade produtiva para exportar, flexibilidade para ajustes no produto, definição da forma de embalagem ao transporte internacional, informação sobre acomodação do produto em pallet e/ou contêiner, inovação/design/sustentabilidade em produto/processo/gestão e se possui Radar documento fundamental de habilitação às ações de comércio exterior.

Com base nestes requisitos são elaboradas demandas do PEIEX para que a empresa possa se qualificar. Ao analisar o Quadro 05, a área de "Comércio Exterior" foi a mais importante demanda sugerida, visto ser um processo relevante na internacionalização via exportações.

No total das 191 demandas elencadas nas seis áreas, o comércio exterior somou 152 (aproximadamente 79,5\%), obtendo representatividade expressiva em conformidade com o propósito da APEX-BRASIL, e justificando a atuação do Núcleo Operacional do Vale do Itajaí. Ainda com relação aos dados das 152 demandas sugeridas (Quadro 05), 57 foram priorizadas (37,6\%), 39 parcialmente priorizadas $(25,6 \%)$ e 56 não foram priorizadas (36,8\%). Outra análise na descrição das demandas do Quadro 05, além do plano de exportação já comentado (93 demandas), o programa governamental de auxílio à exportação (com 28 demandas) é o segundo mais relevante da pesquisa, seguido pelo processo de exportação (18 demandas).

Aqui cabe ressaltar que a maioria das empresas integradas ao PEIEX no segundo semestre de 2018 e em 2019 (janeiro-abril) ainda não tiveram a oportunidade de participar de ações de promoção comercial da APEX-BRASIL e de iniciar o processo de exportação.

\section{CONSIDERAÇÕES FINAIS}

De acordo com o problema de pesquisa, voltado ao índice de atendimento às demandas das empresas que participaram do programa PEIEX/UNIVALI no período de 2017/2019, foram investigadas 191 demandas em uma amostra de 40 empresas. O resultado possibilita identificar informações relevantes para o Núcleo Operacional do Vale do Itajaí na tomada de decisão e planejamento das atividades ligadas à Metodologia PEIEX.

Ao levantar o perfil das empresas quanto à área de atuação, esta pesquisa mostrou uma tendência para os setores têxtil, alimentos e bebidas e metalomecânico. No status de implantação das 191 demandas sugeridas pelos extensionistas, a pesquisa apontou 77 priorizadas, 42 priorizadas parcialmente e 72 não priorizadas, 
ou seja, das sugestões elencadas $40 \%$ foram atendidas e 38\% ainda não foram completamente assistidas.

Ponderando que as propostas apresentadas são necessárias ao processo de internacionalização, no feedback informado pelas empresas no relatório de conclusão não se descarta a intenção de cumpri-las a qualquer momento, o que depende das estratégias de cada organização.

O foco na internacionalização está nas principais recomendações da área funcional de comércio exterior ao mostrar 7 demandas priorizadas na engenharia de exportação. O plano de exportação foi mencionado em todos os relatórios de diagnósticos como uma importante demanda a ser priorizada. $\mathrm{O}$ resultado mostrou 31 melhorias atendidas e 25 parcialmente, mas 37 demandas não foram totalmente priorizadas pelas empresas. $\mathrm{O}$ total de demandas indicadas para a área funcional de Comércio Exterior foram 152, destas, 57 priorizadas, 39 parcialmente priorizadas e 56 não atendidas.

Como fator limitante registra-se que os dados documentais extraídos das visitas às empresas se baseiam nos depoimentos dos gestores quanto ao cumprimento de demandas, neste caso, o extensionista não teve comprovação da implementação.

A partir desse trabalho recomenda-se que os novos atendimentos continuem orientados pela Metodologia PEIEX, na padronização interna do registro das informações e demandas. Da mesma forma, este cenário de demandas cumpridas mostra o empenho (ou não) das empresas, visto o reconhecimento destas à metodologia antes do aceite ao Programa, e o comprometimento com as atividades apresentadas posteriormente.

\section{REFERÊNCIAS}

APEX-BRASIL. APEX-BRASIL lança núcleo do PEIEX em Itajaí. Brasília, 2017. Disponível em: http://www.apexbrasil.com.br/Noticia/APEX-BRASIL-LANCA-NUCLEO-DO-PEIEX-EM-ITAJAI. Acesso em: 29 mar. 2019.

APEX-BRASIL. PEIEX: Manual de Trabalho. ed. rev. e ampl. [S. l.: s. n.], 2013. Pen drive.

APEX-BRASIL. Qualifique sua empresa PEIEX. Disponível em: https://portal. apexbrasil.com.br/qualifique-sua-empresa-PEIEX/ Acesso em: 29 mar. 2019. 
CALOF, J.; BEAMISH, P. W. Adapting To Foreign Markets: Explaining Internationalization. International Business Review. London, v. 4, n. 2, p. 115-131, 1995.

CERVO, A. L. BERVIAN, P. A. Metodologia científica. 5.ed. São Paulo: Prentice Hall, 2012.

CHIAVENATO, I. Administração Geral: fundamentos básicos. 6. ed. São Paulo: Atlas, 2014.

FAYOL, H. Administração Industrial e Geral. São Paulo: Atlas, 1990.

FUNDAÇÃO UNIVERSIDADE DO VALE DO ITAJAÍ. Convênio de cooperação técnica e financeira entre APEX-BRASL e UNIVALI. Convênio de cooperação técnica e financeira 48-06/2016, 15 jun. 2016.

GOEDE, W. Um olhar sob a Velocidade, o Escopo e o Ritmo de Internacionalização. Novas Edições Acadêmicas, 2017.

JOHANSON, J.; VAHLNE, J. Markets as networks: implications for strategymaking. Journal of the Academy of Marketing Science. [S. 1.], v. 39, n. 4, p. 484-491, 2011.

MAXIMIANO, A. C. A. Introdução a Administração. 9. ed. rev. e ampl. São Paulo, Atlas, 2012.

OVIATT, B. M.; MCDOUGALL, P. P. Toward a theory of international new ventures. Journal of International Business Studies. [S. 1.] v. 25, n. 1, p. 45-64, 1994.

ROESCH, S. M. A. Projetos de estágio e de pesquisa em Administração: guia para estágios, trabalhos de conclusão, dissertações e estudos de caso. 3 ed. São Paulo: Atlas, 2010.

ROOT, F.J. Foreign Market Entry Strategies. New York: Lexington, 1994.

SOUZA, E. C. L.; FENILI, R. R. Internacionalização de empresas: perspectivas teóricas e agenda de pesquisa. Revista de Ciências da Administração. [S. 1.] v. 14, n. 33, p. 103-118, ago. 2012. 